\title{
Seasonal Carryover Effects following the Administration of Cortisol to a Wild Teleost Fish
}

\author{
Constance M. O’Connor ${ }^{1, *}$ \\ Kathleen M. Gilmour ${ }^{2}$ \\ Robert Arlinghaus ${ }^{3,4}$ \\ Caleb T. Hasler ${ }^{1}$ \\ David P. Philipp ${ }^{5}$ \\ Steven J. Cooke ${ }^{1,6}$ \\ ${ }^{1}$ Fish Ecology and Conservation Physiology Laboratory, \\ Ottawa-Carleton Institute of Biology, Carleton University, \\ 1125 Colonel By Drive, Ottawa, Ontario K1S 5B6, Canada; \\ ${ }^{2}$ Department of Biology, University of Ottawa, 30 Marie \\ Curie, Ottawa, Ontario K1N 6N5, Canada; ${ }^{3}$ Department of \\ Biology and Ecology of Fishes, Leibniz-Institute of \\ Freshwater Ecology and Inland Fisheries, Müggelseedamm \\ 310, 12587 Berlin, Germany; ${ }^{4}$ Inland Fisheries Management \\ Laboratory, Department of Crop and Animal Sciences, \\ Faculty of Agriculture and Horticulture, Humboldt \\ University of Berlin, Invalidenstrasse 42, 10115 Berlin, \\ Germany; ${ }^{5}$ Illinois Natural History Survey, Institute for \\ Natural Resources Sustainability, University of Illinois, 1816 \\ South Oak Street, Champaign, Illinois 61820; ${ }^{6}$ Institute of \\ Environmental Science, Carleton University, 1125 Colonel By \\ Drive, Ottawa, Ontario K1S 5B6, Canada
}

Accepted 7/8/2010; Electronically Published 10/8/2010

\begin{abstract}
Stress can have sublethal effects that are manifested either immediately or at spatial or temporal scales that are removed from the stress event (i.e., carryover effects). We tested whether a short-term elevation of plasma cortisol would result in seasonal carryover effects in wild largemouth bass Micropterus salmoides. Using exogenous hormone implants, we raised circulating cortisol concentrations in a group of wild fish for approximately $5 \mathrm{~d}$ in October 2007. We then compared activity (velocity, distance traveled) of cortisol-treated animals with that of shamtreated and control animals throughout the winter using an automated acoustic telemetry array. Immediately following treatment, the cortisol-treated fish showed increased activity relative to controls. However, this difference disappeared following the cessation of the elevation of circulating cortisol. During the winter of 2007 to 2008 , the lake experienced a nearly
\end{abstract}

*Corresponding author; e-mail: coconno4@connect.carleton.ca.

Physiological and Biochemical Zoology 83(6):950-957. 2010. (C) 2010 by The University of Chicago. All rights reserved. 1522-2152/2010/8306-0024\$15.00. DOI: $10.1086 / 656286$ complete winterkill event, providing insight into how a transient stress response can influence the response of wild animals to subsequent challenges. Most fish carrying acoustic transmitters succumbed during this winterkill event, but cortisoltreated fish died earlier than fish in other groups and showed a decrease in activity relative to controls and sham-treated fish before mortality. This study provides preliminary evidence of seasonal carryover effects in wild fish and yields insight into the ecological consequences of stress across broad temporal scales.

\section{Introduction}

Carryover effects refer to situations in which conditions during one period affect the outcome of events that occur during a subsequent period. Carryover effects may significantly influence population abundance and dynamics in wild animals (Webster et al. 2002; Norris 2005; Norris and Taylor 2006), but they have rarely been examined in wild populations because of the logistic difficulties associated with quantifying effects that are removed from their cause by large temporal or spatial scales. The few available studies on carryover effects have focused primarily on migratory bird populations. For example, overwintering conditions can affect the subsequent breeding success of barn swallows Hirundo rustico following their migration (Saino et al. 2004). The quality of tropical overwintering habitat also affects the arrival date of American redstarts (Setophaga ruticilla) at their temperate summer breeding grounds, which then influences reproductive success (Norris et al. 2004). Similarly, improving the quality of overwintering habitat improves return rates and long-term survival in American redstarts (Studds and Marra 2005). Intragenerational carryover effects have been investigated to a limited extent in other model systems, including evidence that carryover effects can occur across metamorphosis. For example, the lifetime mating success of adult damselflies (Lestes viridis) is influenced by carryover larval constraints (De Block and Stoks 2005), while tadpole food resources can affect subsequent adult performance in northern red-legged frogs (Rana aurora aurora; Chelgren et al. 2006). However, carryover effects have been virtually unexplored in wild populations without a distinct migratory or metamorphic process to delineate life-history stages.

Wild fish inhabiting highly seasonal environments (i.e., environments with large differences between summer and winter water temperatures) provide a logistically tractable complementary model system with which to study carryover effects. 
In this case, the winter period constitutes a significant natural challenge that punctuates the annual life-history cycle of fish in northern latitudes (Conover 1992) with high condition- and size-dependent winter mortality (Biro et al. 2004). However, little is known about the overwinter ecology of freshwater fish. Recent advances in telemetry technology have revealed that largemouth bass Micropterus salmoides remain active in winter, although at reduced levels relative to the warmer summer season (Hanson et al. 2007). There is some evidence that brown bullhead (Ictalurus nebulosus) and largemouth bass will cease feeding below $10^{\circ} \mathrm{C}$ (Crawshaw 1984), and it is no surprise that even with abundant food supplies, the condition of largemouth bass declines over the winter in northern areas (Fullerton et al. 2000). Smallmouth bass (Micropterus dolomieu) and largemouth bass appear to aggregate in areas with favorable conditions (e.g., high oxygen [Gent et al. 1995]; warm temperature and presence of macrophytes [Karchesky and Bennett 2004]; proximity to conspecifics [Hasler et al. 2007]). Beyond these preliminary studies, nothing is known about how environmental conditions during the favorable summer and fall seasons affect overwintering behavior or survival of wild freshwater fish.

Freshwater fish also constitute an interesting model system in which to study carryover effects because freshwater fish are increasingly exposed to a variety of anthropogenic stressors. These stressors are both chronic (e.g., habitat degradation [Cooke and Suski 2008]; climate change [Pörtner and Farrell 2008]) and acute (e.g., catch-and-release angling [Cooke and Schramm 2007]; release of bycatch in commercial fishing operations [Davis 2002]). Although most of these stressors do not immediately kill fish, they may cause long-term physiological changes that impair the ability of fish to perform essential activities such as finding food, evading predators, reproducing successfully, and resisting disease (Barton 2002). Thus, the quantification of carryover effects is a critical step in managing populations of fish that are routinely exposed to these anthropogenic activities.

The aim of this study was to determine whether experience of a transient stressor resulted in carryover effects using as the model system a wild population of largemouth bass at the northern limit of their range. We used an exogenous pharmacological implant of cortisol, which is the primary glucocorticoid in fish and of wide interest owing to its role in the physiological stress response (Wendelaar-Bonga 1997; Mommsen et al. 1999). Cortisol implants mimic the physiological effects of exposure to a stressor by inducing an elevation of circulating cortisol concentrations (Gamperl et al. 1994). In this study, we experimentally induced a transient 5-d supraphysiological elevation of cortisol in the fall (O'Connor et al. 2009) and then compared the subsequent behavior and mortality rates of cortisol-treated fish with sham-treated and control fish throughout the winter using a remote acoustic twodimensional whole-lake telemetry array (Cooke et al. 2005). During the winter, the study system experienced a winterkill event with nearly complete mortality, a severe ecological challenge that is often associated with hypoxia (Greenbank 1945; Hurst 2007). This winterkill event provided a unique oppor- tunity to assess the effect of transient cortisol elevation on behavior and mortality during a subsequent extreme environmental challenge.

\section{Material and Methods}

\section{Study Site}

Warner Lake is a small (8.2-ha) private research lake in eastern Ontario $\left(44^{\circ} 31^{\prime} \mathrm{N}, 76^{\circ} 22^{\prime} \mathrm{W}\right)$. In 2003, Warner Lake was equipped with a whole-lake acoustic telemetry array that allows near-real-time positioning of fish in the wild (fully described in Cooke et al. 2005). Briefly, 13 hydrophones were positioned strategically throughout the lake so that the locations of fish equipped with transmitters could be tracked with submeter precision in near real time. This system is unique in the world in terms of coverage of an entire lake to assess the behavior and fate of wild freshwater fish. Warner Lake is a closed system for fish, with no potential for immigration or emigration, and the lake is closed to public fishing.

\section{Study Animals and Treatments}

From October 10 to 13, 2007, largemouth bass were captured by rod-and-reel angling from Warner Lake and transported to shore in coolers of lake water. On shore, fish were weighed (to the nearest $\mathrm{g}$ ), and fish greater than $450 \mathrm{~g}$ were deemed suitable to carry the intraperitoneal acoustic transmitters (Model MD$11-18$, mass $=8.4 \mathrm{~g}$ in the air; Lotek Wireless, Newmarket, Ontario) according to the accepted $2 \%$ rule of biotelemetry (where the transmitter must not be greater than $2 \%$ of the animal's total mass; Winter 1983). Suitable fish $(n=25)$ were assigned to one of three treatment groups: control $(n=8$; $638.5 \pm 125.6 \mathrm{~g})$, sham treatment $(n=8 ; 637.6 \pm 72.3 \mathrm{~g})$, and cortisol treatment $(n=9 ; 693.6 \pm 113.0 \mathrm{~g})$. All groups contained fish with the same size distributions. All fish were anesthetized in an induction bath containing $50 \mathrm{MG} \mathrm{L}^{-1}$ clove oil (10\% clove oil emulsified in ethanol; Prince and Powell 2000) in fresh lake water. After loss of equilibrium, fish were placed on a surgery table that allowed the gills to be irrigated with an aerated solution of fresh lake water containing $10 \mathrm{mg}$ $\mathrm{L}^{-1}$ clove oil. The fish were implanted with transmitters following procedures described in Cooke et al. (2003). Cortisoltreated fish were injected intraperitoneally with $10 \mathrm{mg} \mathrm{mL}^{-1}$ of cortisol (hydrocortisone; Sigma H4001, Sigma-Aldrich, St. Louis, MO) emulsified in coconut oil (Cocos nucifera; Sigma C1758, Sigma-Aldrich, St. Louis, MO), at $0.005 \mathrm{~mL} \mathrm{~g}^{-1}$ body weight. This is an established method of elevating circulating cortisol in fish in a controlled manner (Gamperl et al. 1994). A laboratory pilot study confirmed that in this species, this dose raises plasma cortisol for approximately $5 \mathrm{~d}$ to $\sim 2,000 \mathrm{ng}$ $\mathrm{mL}^{-1}$ (O'Connor et al. 2009), a supraphysiological level that is higher than that elicited by exposure to a typical stressor such as exhaustive exercise (O'Connor et al. 2009). Sham-treatment fish were given intraperitoneal injections of pure coconut oil at $0.005 \mathrm{~mL} \mathrm{~g}^{-1}$ body weight. Control fish were not injected. 
All fish were immediately released from the same location on regaining equilibrium.

\section{Behavioral Data Collection and Analyses}

The acoustic transmitters were programmed to relay positional information to the hydrophones every $59.5 \mathrm{~s}$. Information from the hydrophones was then relayed through submerged cables to receivers on the shore, where the information was stored on flash cards. Information was collected continuously throughout the study period excluding November 28-December 7, 2007, when the receiver was not functioning because of a power outage. Raw position solutions were generated by triangulating acoustic signals received from a single tag at a single point in time by three or more hydrophones within the array using the two-dimensional positioning engine within the program BioMAP (Lotek Wireless, Newmarket, Ontario). Erroneous positions were removed through BioMAP's filtering program (for a full description, see Hanson et al. 2007). Filtered raw position data were then queried to generate tables of activity information (distance traveled and velocity) for each fish. The instantaneous distance traveled $(\mathrm{m})$ between each signal transmission was calculated using the Pythagorean theorem, assuming that each fish traveled between positions while maintaining the same depth. Fish movement was restricted to a depth between 6.5 and $5.5 \mathrm{~m}$ when the lake was covered with ice (Hanson et al. 2007), and this limited change in depth throughout the winter months minimized the effect of this variable on the measurements of horizontal movements during this period. Instantaneous velocity $\left(\mathrm{m} \mathrm{s}^{-1}\right)$ was determined by dividing the instantaneous distance moved by the time between signal transmissions. Mortality of individuals was determined by importing the raw position data to ArcMAP, version 9 (ESRI, Redlands, CA), and observing daily positional tracks. Fish were deemed to be dead once tracks indicated extremely reduced and nondirectional patterns that could be accounted for by water movement. Death dates were confirmed using minimum convex polygons (Rogers and White 2007).

We sought to assess both the short- and long-term behavioral consequences of a short-term elevation of circulating cortisol. As such, we examined the behavioral data at two scales. First, to assess short-term behavioral consequences, we examined activity and spatial behavior during the first $5 \mathrm{~d}$ following transmitter implantation. Second, to assess the long-term behavioral consequences, we plotted general activity trends for all treatment groups over the winter (running 5 -d means). Using watertemperature profiles (collected using the telemetry array from $n=8$ fish implanted with transmitters equipped with temperature sensors for a different study; Hasler et al. 2009), we then selected three representative 5 -d periods to examine the data in more detail (fall, November 8-12; early winter, December 26-30; late winter, February 13-17). These days represented periods of stable water temperature with environmental conditions that are typical of the periods of interest. During all 5d periods, we examined activity by calculating mean daily dis- tance traveled $(\mathrm{m})$ and mean velocity $\left(\mathrm{m} \mathrm{s}^{-1}\right)$ over the entire 5-d period.

\section{Statistical Analyses}

A product-limit log-rank survival analysis was conducted to determine whether the timing of mortality differed among the treatment groups. This test compares the mean length of time that fish in each group survived following the date of transmitter implantation. ANOVA tests were conducted to determine whether there was a difference in mean daily distance traveled and mean velocity among treatment groups during the first $5 \mathrm{~d}$ after treatment. For the long-term data, two-way ANOVA models with repeated measures were run for distance traveled and mean velocity using the three representative 5-d periods. Following significant two-way ANOVA models with repeated measures, we ran separate one-way ANOVAs at each selected 5-d time period to better understand the relationships among treatment groups. Tukey's post hoc tests were employed following all significant one-way ANOVAs to determine where among groups the differences lay. It is important to note that only fish that were alive during all representative periods were used for the repeated-measures ANOVAs. The assumptions of equality of variances and normal distribution were tested and met for all analyses. All analyses were performed in the statistical package JMP, version 7.0.1 (SAS Institute, Cary, NC). The level of significance for all tests $(\alpha)$ was assessed at 0.05. All results are presented as means \pm SE.

\section{Results}

All fish in all treatments survived the tagging and manipulation procedures, with no mortality observed in any treatment group until late December, more than 2 mo after tagging. Interestingly, the timing of mortality differed significantly among the treatment groups. The cortisol-treated individuals succumbed sig-

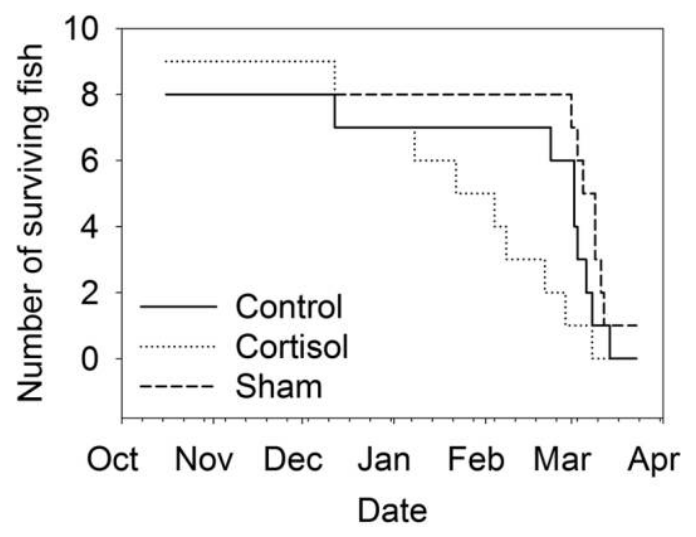

Figure 1. Surviving largemouth bass from all treatment groups between October 18, 2007, and March 15, 2008. There is a highly significant effect of treatment group on survival rate, with cortisol-treated fish succumbing earlier in the winter than fish in the other treatment groups. 

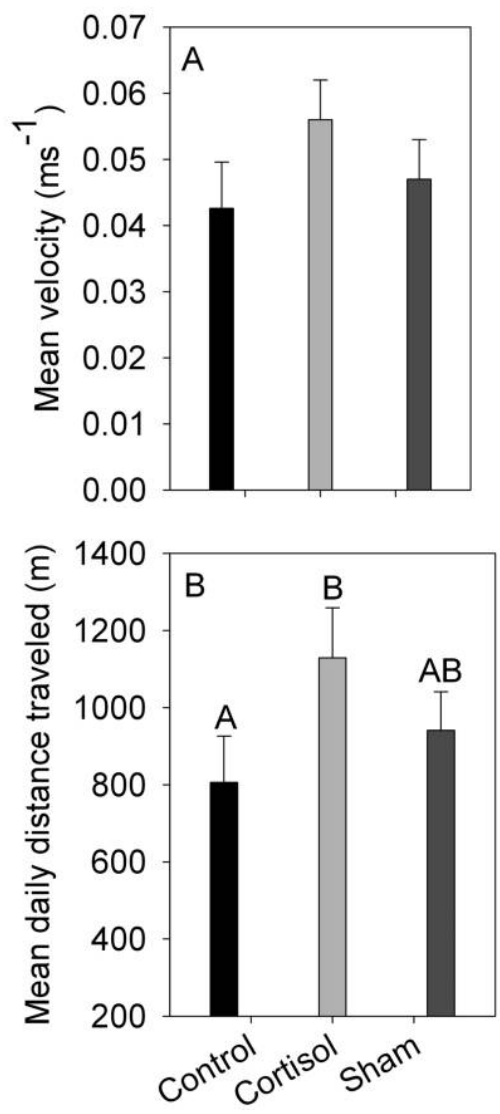

Figure 2. Short-term activity of largemouth bass from all treatment groups (i.e., activity during the first $5 \mathrm{~d}$ after transmitter implantation). There was a significant difference among the groups in mean daily distance traveled $(B)$, with higher activity in the cortisol-treated group.

nificantly earlier in the winter than individuals in the other groups (log-rank survival analysis, $\lambda^{2}=11.71, \mathrm{df}=2, P<$ 0.01; Fig. 1).

There was a significant effect of treatment on swimming activity during the first $5 \mathrm{~d}$ after treatment and transmitter implantation (Fig. 2). There was no difference in mean velocity of fish among treatment groups $\left(F_{2,22}=1.51, P=0.24\right.$; Fig. $2 A)$. However, fish treated with cortisol traveled greater daily distances than did fish in the control group $\left(F_{2,22}=3.76\right.$, $P=0.04$; Fig. $2 B$ ).

In the long term, there was a slight trend for cortisol-treated fish to display increased activity throughout the winter. There was a large divergence between the cortisol-treated fish and the other treatment groups during the late winter, with activity in the sham-treated and control groups increasing in the late winter while activity decreased slightly in the cortisol group (Fig. 3). Using representative 5-d periods to examine these relationships in detail, a two-way ANOVA with repeated measures revealed significant differences for both mean velocity (Fig. $4 A$ ) and mean daily distance traveled among the treatment groups (Fig. 4B). For both mean velocity and mean daily distance traveled, there was an interaction between seasonal period and treatment group (mean velocity Roy's maximum root $F_{2,16}=$ 5.51, $P=0.02$ [Fig. 4A]; mean daily distance traveled Roy's maximum $\operatorname{root} F_{2,16}=5.93, P=0.01$ [Fig. $4 B$ ]). Separate oneway ANOVAs at each time period revealed that while there was a trend for cortisol-treated fish to display increased activity during the early winter, differences in activity were only significant during the late winter period, when the activity of control and sham-treated fish increased significantly and the activity of cortisol-treated fish decreased (mean velocity $F_{2,18}=3.874, P=0.043$ [Fig. $4 \mathrm{~A}$ ]; mean daily distance traveled $F_{2,18}=4.091, P=0.037$ [Fig. $\left.4 B\right]$ ).

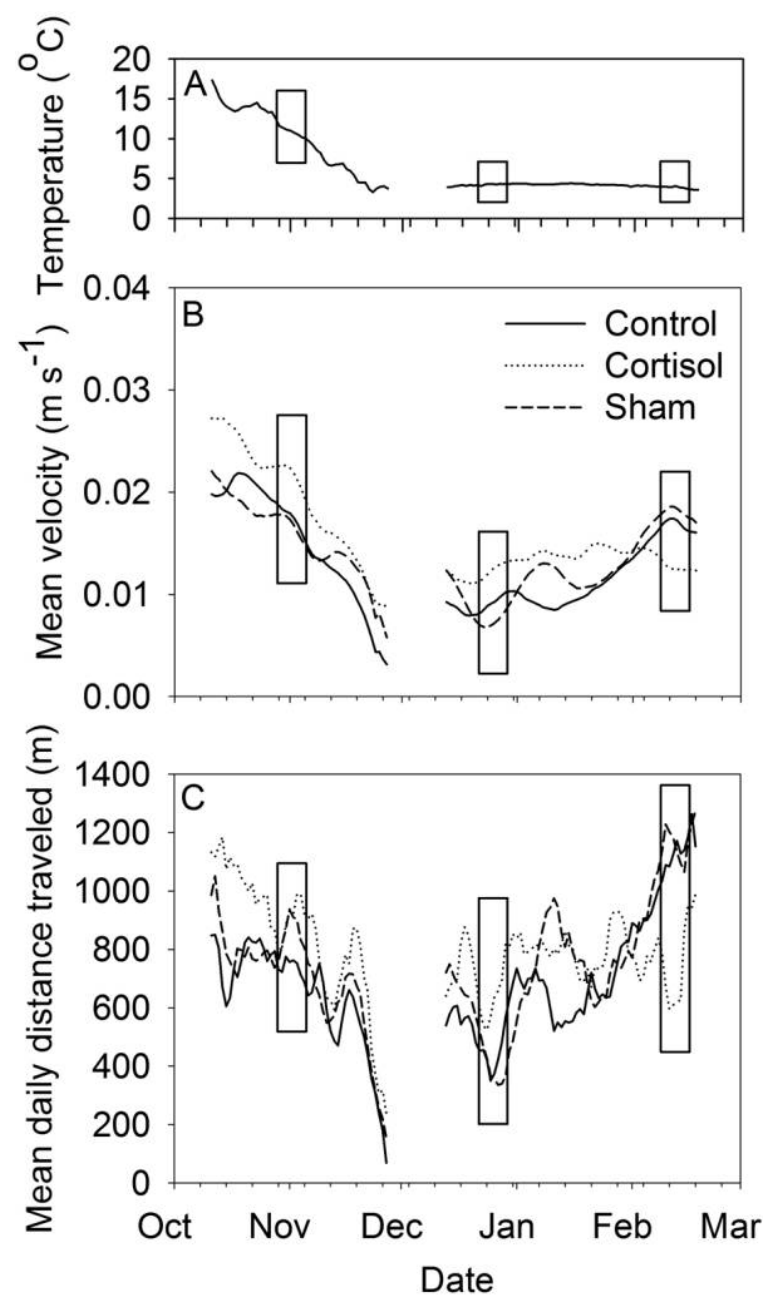

Figure 3. Water temperature $(A)$ and long-term activity $(B, C)$ of largemouth bass from all treatment groups between October 18, 2007, and February 20, 2008. 5-d running means for mean velocity $(B)$ and daily distance traveled $(C)$ show general activity trends through the winter. A power outage occurred from November 28 to December 7, and because data are plotted as 5 - $\mathrm{d}$ running means, the first data point following the power outage occurs on December 12. Boxes indicate the 5 - $d$ periods used for further statistical analysis. 

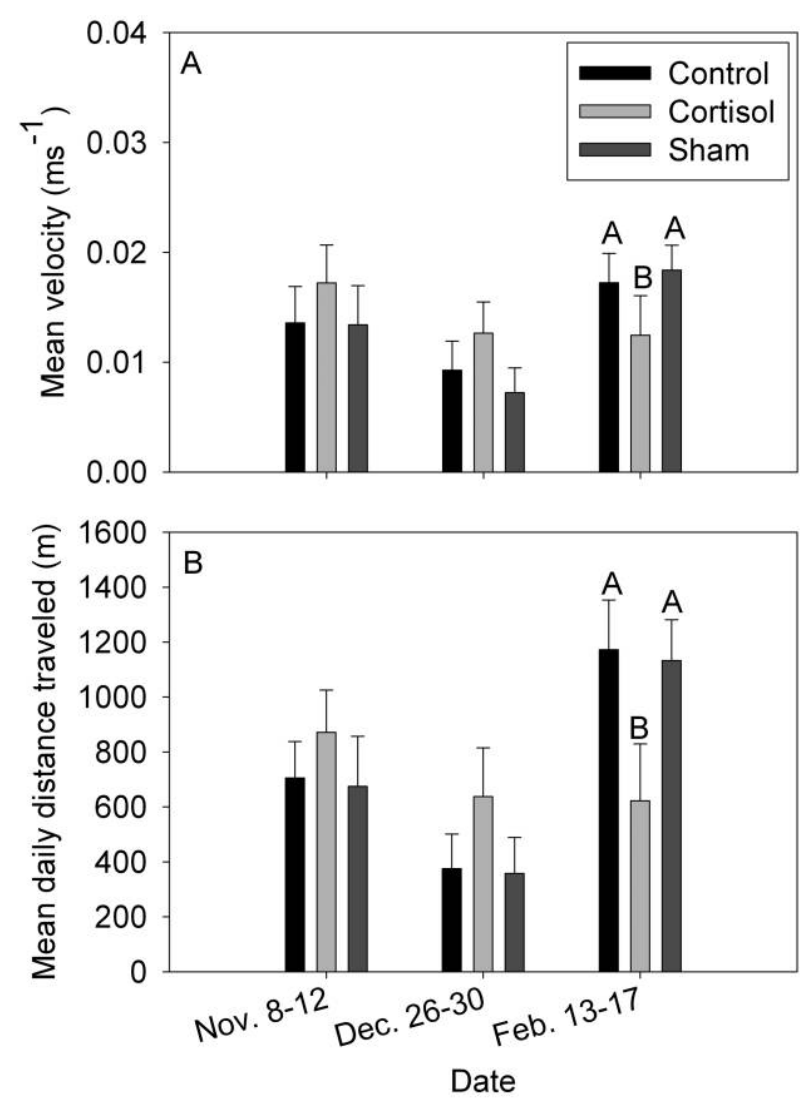

Figure 4. Long-term activity of largemouth bass from all treatment groups; that is, activity during representative 5 - $d$ periods in the fall (November 8-12), early winter (December 26-30), and late winter (February 13-17). There is a significant interaction between time period and treatment group for both mean velocity $(A)$ and mean daily distance traveled $(B)$ driven by differences between the cortisol-treated fish and other treatment groups during the late winter.

\section{Discussion}

We present evidence that a transient elevation of plasma cortisol during the fall can result in carryover effects across seasons. Wild largemouth bass that experienced cortisol treatment during the fall suffered accelerated mortality and displayed altered behavior when compared with sham-treated or control fish during a subsequent winterkill event. While these results may not be typical of a more benign winter, they provide novel insight into how stress effects may operate across seasons and multiple challenges in wild populations.

It is important to note that the cortisol administered in this study generated supraphysiological concentrations of circulating cortisol (O'Connor et al. 2009). In this study, the field setting precluded analysis of pilot samples before the full experiment was initiated, and the result was that the doses selected, which were based largely on literature for salmonid fish (Gamperl et al. 1994), elicited plasma cortisol concentrations in largemouth bass that were an order of magnitude higher than desired. Despite the pharmacological dose, fish exhibited a typical glucose response to elevated plasma cortisol (see O'Connor et al. 2009), and we observed no immediate mortality in the cortisol-treated group (Fig. 1). While acknowledging this methodological limitation, our examination of potential carryover effects in a fish provides unique insight into the physiological mechanisms that drive whole-animal consequences of stress across a broad temporal scale and generates a framework for further studies on this topic. The use of exogenous cortisol administration (particularly of a pharmacological dose) is a first step in testing the possibility of carryover effects in a wild fish population. Further research is necessary to understand whether a physiological stress response would cause similar long-term carryover effects.

A winterkill event is a rapid phenomenon associated with hypoxic conditions under ice, and it is common in small northern lakes dominated by centrarchids (Greenbank 1945; Hurst 2007). While we did not measure dissolved oxygen throughout the winter, the extraordinarily heavy snowpack during the winter of 2007-2008 caused hypoxic conditions and subsequent winterkills in many small lakes in eastern Ontario (S. Smithers, Ontario Ministry of Natural Resources, personal communication). It is noteworthy that the majority of the fish in the sham-treated and control groups died within a very short period of time, between March 2 and 14, 2008 (Fig. 1), that was also consistent with a rapid winterkill event. The cortisoltreated fish, however, suffered a steady rate of mortality throughout the winter (Fig. 1). This mortality pattern suggests that cortisol treatment during the fall was associated with accelerated mortality throughout the winter and may have been unrelated to the winterkill event. Further research is needed to determine whether differences in overall mortality among the treatment groups would occur under more typical winter conditions. However, a recent study by Goutte et al. (2010) demonstrated that short-term (2-d) exogenous elevation of circulating corticosterone negatively affected long-term (2-yr) survival in black-legged kittiwakes (Rissa tridactyla), providing additional support for the hypothesis that exogenous administration of glucocorticoids may increase mortality.

In addition to treatment effects on survival, we found differences in behavior among the treatment groups. During the first $5 \mathrm{~d}$ after treatment, the cortisol-treated fish displayed elevated activity when compared with the control treatment group (Fig. 2). Our data documenting elevated activity as a result of cortisol treatment in a wild free-swimming fish complement those of previous laboratory studies. In rainbow trout Oncorhynchus mykiss, chronic cortisol elevation is associated with a decrease in aggressive locomotor activity when an individual is faced with a conspecific but no difference in locomotion when it is undisturbed (Øverli et al. 2002). In the same species, cortisol elevation is also associated with a decrease in aggression and social status (Gilmour et al. 2005), but no differences in swimming performance were found (Gregory and Wood 1999). Taken together, these results demonstrate that laboratory studies may not capture the full range of behaviors displayed by wild free-swimming fish during an endocrine stress response. Interestingly, the activity difference in this study was 
manifested as an increase in distance traveled without an increase in mean velocity. This suggests that fish subjected to the cortisol treatment decreased their time spent resting rather than increasing swimming velocity while moving. This pattern is consistent with previous studies on Gambel's white-crowned sparrows (Zonotrichia leucophrys gambelii), where corticosterone treatment decreased resting behavior (Breuner et al. 1998). It is possible that the short-term response to an elevation of circulating cortisol represents an increase in avoidance behavior as the animal attempts to remove itself from an adverse stimulus (Wingfield et al. 1998).

The activity levels of cortisol-treated fish were reduced when compared with control and sham-treated fish during the late winter, more than 4 mo after circulating cortisol levels would have returned to control levels. Typically, largemouth bass in the Warner Lake system decrease activity as water temperatures drop in the fall and then increase activity slowly through the winter as the animals acclimatize to the consistent cold temperatures (Hanson et al. 2007; Hasler et al. 2009). In this study, all treatment groups displayed the expected pattern until the final weeks before the winterkill event, when the sham-treated and control individuals increased their activity and the cortisoltreated fish further reduced their activity. A physiological explanation of these behavioral differences may be related to energetics. Elevation of cortisol is known to reduce feeding and body condition in laboratory studies (Gregory and Wood 1999; Mommsen et al. 1999). Winter is energetically demanding and causes a loss of body condition even under favorable circumstances (Fullerton et al. 2000). Any loss of body condition in the fall as a result of transient cortisol elevation likely carried a cost throughout the winter for the cortisol-treated animals. It is also possible that cortisol-treated fish expended more energy through the winter months, with the nonsignificant trend for increased activity lasting until late winter (Fig. 3). Poor body condition and low energetic stores may have limited the behavioral responses of the animals and also may have resulted in the observed accelerated mortality.

An alternative explanation is related to the effect of chronic cortisol elevation on hypothalamus-pituitary-interrenal (HPI)axis function. Elevation of circulating cortisol inhibits HPI-axis activity through a negative feedback loop (Mommsen et al. 1999). Chronic elevation of circulating cortisol therefore inhibits an acute cortisol response when individuals are faced with a secondary stressor (Barton et al. 1987; Balm et al. 1994; Basu et al. 2002). In black-legged kittiwakes, administration of corticosterone resulted in decreased long-term survival relative to sham-implanted animals (Goutte et al. 2010). Experimental work demonstrated that the acute glucocorticoid response in kestrels Falco tinninculus was absent $8 \mathrm{~d}$ after cortisol administration (Müller et al. 2009), and Goutte et al. (2010) suggest that elevated corticosterone may have altered the longer-term ability of black-legged kittiwakes to launch an appropriate stress response when faced with natural stressors, thus leading to decreased survival. Further experimental work is necessary to explore the persistence of HPI-axis suppression following a chronic stressor. However, a loss of HPI-axis function may have contributed to differences in behavioral responses during the late winter between cortisol-treated and control and shamtreated fish in this study.

In summary, this study provides initial evidence that an elevation of circulating cortisol in the fall is associated with accelerated mortality and differences in behavior during the subsequent winter that included a winterkill event. In this case, the elevation of circulating cortisol and the winter conditions were severe. Further research is necessary to understand and quantify seasonal carryover effects across a range of conditions. Research of this kind will increase our understanding of stressinduced physiological changes at the organismal level and will directly benefit our knowledge of the population biology of wild animals (Calow and Sibly 1990) as well as our understanding of the ecological and evolutionary consequences of stress (Calow and Forbes 1998).

\section{Acknowledgments}

All fish were sampled under an Ontario Ministry of Natural Resources scientific collection permit and handled in accordance with the guidelines of the Canadian Council on Animal Care. This research was supported by Natural Sciences and Engineering Research Council discovery grants to S.J.C. and K.M.G., the projects Adaptfish (Gottfried-Wilhelm-Leibniz-Community, http:// www.adaptfish.igb-berlin.de) and Besatzfisch (German Ministry for Education and Research, Program on Social-Ecological Research, grant 01UU0907, http://www.besatz-fisch.de) to R.A., and a Research Achievement Award from Carleton University to S.J.C. The lead author was supported by a Fisheries Research Award from the Ontario Federation of Anglers and Hunters, an Ontario Graduate Scholarship in Science and Technology, and by Carleton University. We also wish to thank the Warner Lake Ecological Observatory Consortium and Lotek Wireless for continued support, members of the Cooke Lab for assistance with fieldwork, and Ryan Norris and anonymous referees who provided helpful comments on earlier versions of this article.

\section{Literature Cited}

Balm P.H.M., P. Pepels, S. Helfrich, M.L.M. Hovens, and S.E. Wendelaar-Bonga. 1994. Adrenocorticotropic hormone in relation to interrenal function during stress in tilapia (Oreochromis mossambicus). Gen Comp Endocrinol 96:347360.

Barton B.A. 2002. Stress in fish: a diversity of responses with particular references to changes in circulating corticosteroids. Integr Comp Biol 42:517-525.

Barton B.A., C.B. Schreck, and L.D. Barton. 1987. Effects of chronic cortisol administration and daily acute stress on growth, physiological conditions, and stress responses in juvenile rainbow trout. Dis Aquat Org 2:173-185.

Basu N., C.J. Kennedy, P.V. Hodson, and G.K. Iwama. 2002. Altered stress responses in rainbow trout following a dietary 
administration of cortisol and $\beta$-napthoflavone. Fish Physiol Biochem 25:131-140.

Biro P.A., A.E. Morton, J.R. Post, and E.A. Parkinson. 2004. Winter lipid depletion and mortality of age-0 rainbow trout (Oncorhynchus mykiss). Can J Fish Aquat Sci 61:1513-1519.

Breuner C.W., A.L. Greenberg, and J.C. Wingfield. 1998. Noninvasive corticosterone treatment rapidly increases activity in Gambel's white-crowned sparrow (Zonotrichia leucophrys gambelii). Gen Comp Endocrinol 11:386-394.

Calow P. and V.E. Forbes. 1998. How do physiological responses to stress translate into ecological and evolutionary processes? Comp Biochem Physiol A 120:11-16.

Calow P. and R.M. Sibly. 1990. A physiological basis of population processes: ecotoxicological implications. Funct Ecol 4:283-288.

Chelgren N.D., D.K. Rosenberg, S.S. Heppell, and A.I. Gitelman. 2006. Carryover aquatic effects on survival of metamorphic frogs during pond emigration. Ecol Appl 16:250261.

Conover D.O. 1992. Seasonality and the scheduling of life history at different latitudes. J Fish Biol 41:161-178.

Cooke S.J., B.D.S. Graeb, C.D. Suski, and K.G. Ostrand. 2003. Effects of suture material on incision healing, growth and survival of juvenile largemouth bass implanted with miniature radio transmitters: case study of a novice and experienced fish surgeon. J Fish Biol 62:1366-1380.

Cooke S.J., G.H. Neizgoda, K.C. Hanson, C.D. Suski, F.J.S. Phelan, R. Tinline, and D.P. Philipp. 2005. Use of CDMA acoustic telemetry to document 3-D positions of fish: relevance to the design and monitoring of aquatic protected areas. Mar Technol Soc J 39:17-27.

Cooke S.J. and H.L. Schramm. 2007. Catch-and-release science and its application to conservation and management of recreational fisheries. Fish Manag Ecol 14:73-79.

Cooke S.J. and C.D. Suski. 2008. Ecological restoration and physiology: an overdue integration. BioScience 58:957-968.

Crawshaw L.J. 1984. Low-temperature dormancy in fish. Am J Physiol 246:479-486.

Davis M.W. 2002. Key principles for understanding fish bycatch discard mortality. Can J Fish Aquat Sci 59:1834-1843.

De Block M. and R. Stoks. 2005. Fitness effects from egg to reproduction: bridging the life history transition. Ecology 86 : 185-197.

Fullerton A.H., J.E. Garvey, R.A. Wright, and R.A. Stein. 2000. Overwinter growth and survival of largemouth bass: interactions among size, food, origin, and winter severity. Trans Am Fish Soc 129:1-12.

Gamperl A.K., M.M. Vijayan, and R.G. Boutilier. 1994. Experimental control of stress hormone levels in fishes: techniques and applications. Rev Fish Biol Fish 4:215-255.

Gent R., J. Pitlo Jr., and T. Boland. 1995. Largemouth bass response to habitat and water quality rehabilitation in a backwater of the upper Mississippi River. N Am J Fish Manag 15:784-793.

Gilmour K.M., J.D. DiBattista, and J.C. Thomas. 2005. Phys- iological causes and consequences of social status in salmonid fishes. Integr Comp Biol 45:263-273.

Goutte A., F. Angelier, J. Welcker, B. Moe, C. Clement-Chastel, G.W. Gabrielsen, C. Bech, and O. Chastel. 2010. Long-term survival effect of corticosterone manipulation in black-legged kittiwakes. Gen Comp Endocrinol 167:246-251.

Greenbank J. 1945. Limnological conditions in ice-covered lakes, especially as related to winterkill of fish. Ecol Monogr 15:343-392.

Gregory T.R. and C.M. Wood. 1999. The effects of chronic plasma cortisol elevation on the feeding behavior, growth, competitive ability, and swimming performance of juvenile rainbow trout. Physiol Biochem Zool 72:286-295.

Hanson K.C., S.J. Cooke, C.D. Suski, G. Niezgoda, F.J.S. Phelan, R. Tinline, and D.P. Philipp. 2007. Assessment of largemouth bass (Micropterus salmoides) behavior and activity at multiple spatial and temporal scales utilizing a whole-lake telemetry array. Hydrobiologia 582:243-256.

Hasler C.T., K.C. Hanson, S.J. Cooke, R. Tinline, C.D. Suski, G. Niezgoda, F.J.S. Phelan, and D.P. Philipp. 2007. Frequency, composition and stability of associations among individual largemouth bass (Micropterus salmoides) at diel, daily and seasonal scales. Ecol Freshw Fish 16:417-424.

Hasler C.T., C.D. Suski, K.C. Hanson, S.J. Cooke, D.P. Philipp, and B.L. Tufts. 2009. Effect of water temperature on laboratory swimming performance and natural activity levels of adult largemouth bass. Can J Zool 87:589-596.

Hurst T.P. 2007. Causes and consequences of winter mortality in fishes. J Fish Biol 71:315-345.

Karchesky C.M. and D.H. Bennett. 2004. Winter habitat use by adult largemouth bass in the Pend Orielle River, Idaho. N Am J Fish Manag 24:577-585.

Mommsen T.P., M.M. Vijayan, and T.W. Moon. 1999. Cortisol in teleosts: dynamics, mechanisms of action, and metabolic regulation. Rev Fish Biol Fish 9:211-268.

Müller C., B. Almasi, A. Roulin, C.W. Breuner, S. Jenni-Eiermann, and L. Jenni. 2009. Effects of corticosterone pellets on baseline and stress-induced corticosterone and corticosteroid-binding-globulin. Gen Comp Endocrinol 160:59-66.

Norris D.R. 2005. Carry-over effects and habitat quality in migratory animals. Oikos 109:178-186.

Norris D.R., P.P. Marra, T.K. Kyser, T.W. Sherry, and L.M. Ratcliffe. 2004. Tropical winter habitat limits reproductive success on the temperate breeding grounds in a migratory bird. Proc R Soc B 271:59-64.

Norris D.R. and C.M. Taylor. 2006. Predicting the consequences of carry-over effects for migratory populations. Biol Lett 2: 148-151.

O’Connor C.M., K.M. Gilmour, R. Arlinghaus, G. Van Der Kraak, and S.J. Cooke. 2009. Stress and parental care in a wild teleost fish: insights from exogenous supraphysiological cortisol implants. Physiol Biochem Zool 82:709-719.

Øverli Ø., S. Kotzian, and S. Winberg. 2002. Effects of cortisol on aggression and locomotor activity in rainbow trout. Horm Behav 42:53-61. 
Pörtner H.O. and A.P. Farrell. 2008. Physiology and climate change. Science 322:690-692.

Prince A. and C. Powell. 2000. Clove oil as an anesthetic for invasive field procedures on adult rainbow trout. $\mathrm{N}$ Am J Fish Manag 20:1029-1032.

Rogers K.B. and G.C. White. 2007. Analysis of movement and habitat use from telemetry data. Pp. 625-676 in C.S. Guy and M.L. Brown, eds. Analysis and Interpretation of Freshwater Fisheries Data. American Fisheries Society, Bethesda, MD.

Saino N., T. Szép, R. Ambrosini, M. Romano, and A.P. Møller. 2004. Ecological conditions during winter affect sexual selection and breeding in a migratory bird. Proc R Soc B 271: 681-686.

Studds C.E. and P.P. Marra. 2005. Nonbreeding habitat occu- pancy and population processes: an upgrade experiment with a migratory bird. Ecology 86:2380-2385.

Webster M.S., P.P. Marra, S.M. Haig, S. Bensch, and R.T. Holmes. 2002. Links between worlds: unraveling migratory connectivity. Trends Ecol Evol 17:76-83.

Wendelaar-Bonga S.E. 1997. The stress response in fish. Physiol Rev 77:591-625.

Wingfield J.C., D.L. Maney, C.W. Breuner, J.D. Jacobs, S. Lynn, M. Ramenofsky, and R.D. Richardson. 1998. Ecological bases of hormone-behavior interactions: the "emergency life history stage." Am Zool 38:191-206.

Winter J.D. 1983. Underwater biotelemetry. Pp. 371-395 in L.A. Nielson and D.L. Johnson, eds. Fisheries Techniques. American Fisheries Society, Bethesda, MD. 